\title{
Characterization and Application of N-doped Carbon Nanodots from Molasses Produced by Microwave- Assisted Extraction Method for Photocatalytic Degradation of Methylene Blue
}

\author{
Mentik Hulupi ${ }^{1}$, Haryadi $^{2}$, Muahamd Ariq Al Badar ${ }^{3}$, Ahya Sularasa $^{4}$ \\ \{hulupimentik@yahoo.com ${ }^{1}$, haryadi@polban.ac.id ${ }^{2}$, ariqalbadar14@gmail.com $\left.{ }^{3}\right\}$ \\ Politeknik Negeri Bandung, Indonesia ${ }^{1,2,3,4}$
}

\begin{abstract}
Methylene Blue brings harm to the environment as it is disposed to the river bodies as waste. This affects the life of aquatic biota and the health of communities that use the river water. To overcome this problem, Nitrogen-doped Carbon Nanodots (Ndoped CNDs) as photocatalysts can be used as an alternative in degrading Methylene Blue (MB) through the photocatalytic process. The potential of N-doped CNDs to degrade MB through the photocatalytic process became the aim of this study. N-doped CNDs from molasses have been successfully synthesized using $\mathrm{H} 2 \mathrm{O} 2$ followed by the MicrowaveAssisted Extraction (MAE) method. The properties of synthesized N-doped CNDs were characterized by UV light $365 \mathrm{~nm}$, UV-Vis spectrophotometer, FTIR, and HRTEM. The optimum condition of photocatalytic degradation of $\mathrm{MB}$ exhibited at $\mathrm{pH} 10$ with the addition of $3 \mathrm{~mL} \mathrm{~N}$-doped CNDs under 14.5 W Philips LED irradiation with 97.2\% degradation efficiency.
\end{abstract}

Keywords: Methylene Blue, N-doped Carbon Nanodots, Molasses, Photocatalysts

\section{Introduction}

The growth increasing of the textile industry in Indonesia in 2019 reached $18.98 \%$, up $8.73 \%$ from the previous year. The number of jobs available to the community becomes wider as the growth of the industrial sector increased. However, growth in the textile industry also harms the environment due to the increasing number of effluent discharges (effluents) which still contain harmful dyes into river bodies.

One of the dyes used by the textile industry is methylene blue (MB). Methylene blue is a synthetic cationic dye that is toxic and carcinogenic, can cause eye damage in humans and aquatic animals, and can irritate the skin and digestive system [1]. It is very soluble in water, has high color stability, and has a complex aromatic structure that makes methylene blue difficult to be removed and degraded. Therefore this compound is still present in wastewater with harmful concentrations, thus disrupt the lives of aquatic biota and the health of surrounding communities that use river water for domestic needs. The number of MB discharged into the environment has been regulated by LH RI Regulation No. 14 of 2013 and East Java Governor Decree No. 45 of 2002 which states that the amount of MB allowed to be discharged into the environment is only $0.5 \mathrm{mg} / \mathrm{L}$. 
To overcome this problem, N-doped Carbon Nanodots (N-doped CNDs) are present as photocatalysts which can be used as alternatives to degrade MB through the photocatalytic process. The semiconductor properties of N-doped CNDs allow this material to oxidize compounds into simpler molecules, and can even mineralize them into $\mathrm{CO} 2$ when illuminated by light through photocatalytic reactions. Its non-toxic nature and high water solubility [2] makes N-doped CNDs very easy to apply and environmentally friendly. By-products such as molasses can be used as a source of carbon in the manufacture of N-doped CNDs so that this material can be synthesized very easily and cheaply with Microwave-Assisted Extraction (MAE) method.The mechanism of photocatalytic reactions is shown in Figure 1. The reaction equation is as follows [3]:

1. Photon absorption by N-doped CNDs

$$
\text { N-doped CNDs }+ \text { hv } \quad \rightarrow \text { e-pv }+ \text { h+ }
$$

2. Reduction of dissolved oxygen

$$
(\mathrm{O} 2) \mathrm{ads}+\mathrm{e}-\mathrm{pk} \quad \rightarrow \mathrm{O} 2-\bullet
$$

3. Neutralization of $\mathrm{OH}-$ by $\mathrm{h}+$ to produce $\mathrm{OH} \cdot$ radicals

$$
(\mathrm{H} 2 \mathrm{O} \longleftrightarrow \mathrm{OH}-+\mathrm{H}+)+\mathrm{h}+\mathrm{pv} \quad \rightarrow \mathrm{OH} \bullet+\mathrm{H}+
$$

4. Neutralization $\bullet \mathrm{O} 2$ - by $\mathrm{H}+$

$$
\mathrm{O} 2-\bullet+\mathrm{H}+\quad \rightarrow \cdot \mathrm{HO}_{2}
$$

5. Formation of hydrogen peroxide

$$
2 \cdot \mathrm{HO} 2 \rightarrow \mathrm{H} 2 \mathrm{O} 2+\mathrm{O} 2
$$

6. Decomposition of $\mathrm{H} 2 \mathrm{O} 2$ into $\mathrm{OH} \cdot$ radicals

$$
\mathrm{H} 2 \mathrm{O} 2+\mathrm{e}-\quad \rightarrow \mathrm{OH}_{-}+\mathrm{OH}^{\bullet}
$$

7. $\mathrm{MB}$ decomposition by $\mathrm{OH} \bullet$

$$
\mathrm{MB}(\mathrm{aq})+\mathrm{OH} \bullet \quad \rightarrow \text { Degradation Product }
$$




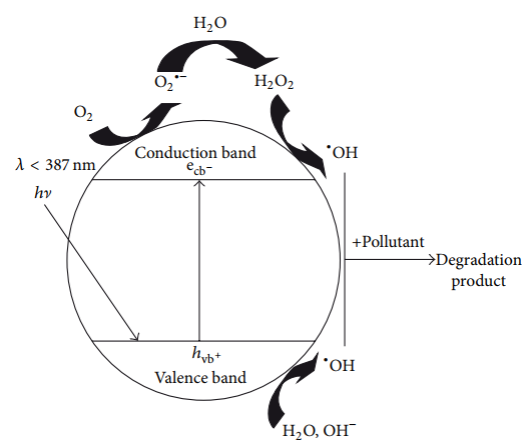

Fig. 1. Mechanisms of Photocatalytic Reaction in Degradating Organic Compounds[4].

$\mathrm{OH} \bullet$ radicals can attack $\mathrm{R}-\mathrm{S}+=\mathrm{R}$ functional groups in MB structures that interact directly with the photocatalyst surface due to colombic interactions that are influenced by $\mathrm{pH}$. The initial step of MB degradation is breaking the bonding of the functional group $\mathrm{R}-\mathrm{S}+=\mathrm{R}$ in the $\mathrm{MB}$ structure to become $\mathrm{R}-\mathrm{S}(=\mathrm{O})-\mathrm{R}, \mathrm{R}-\mathrm{SO} 2-\mathrm{R}, \mathrm{R}-\mathrm{SO} 3 \mathrm{H}-\mathrm{R}$ which then becomes $\mathrm{SO} 42$ and phenol which is a product the end of MB degradation [5].

\section{Experimental Section}

Equipment used in this study included glassware such as measuring pipettes, beaker glass, stirring rods, dropper pipettes, measuring cylinder, burettes, petri dish, magnetic stirring, vials bottles, $365 \mathrm{~nm}$ UV, $254 \mathrm{~nm} 11 \mathrm{~W}$ UV light, $14.5 \mathrm{~W}$ Philips LED, photoreactor with $40 \mathrm{~cm} \mathrm{x}$ $40 \mathrm{~cm}$ x $40 \mathrm{~cm}$ dimension, microwave, Labo visible spectrophotometer, SHIMADZU UV-Vis spectrophotometer, High Speed Centrifuge Benchtop, High Resolution Transmission Electron Microscope (HRTEM), and Fourier Transform Infrared (FTIR).

The materials used in this study include molasses, urea, methylene blue solids, demineralized water, $\mathrm{NaOH}, 0.1 \mathrm{~N} \mathrm{NaOH}, 0.1 \mathrm{~N} \mathrm{HCl}$, and $50 \% \mathrm{H}_{2} \mathrm{O}_{2}$. The method of synthesis of N-doped Carbon Nanodots was modified from the method carried out by Das et al., 2014 in his journal entitled "Carbon Nanodots From Date Molasses: New Nanolights for the In Vitro Scavenging Of Reactive Oxygen Species" [6]. $50 \mathrm{~g}$ of molasses, $5 \mathrm{~g}$ of urea (as nitrogen dopant), and also $1.5 \mathrm{~g}$ of $\mathrm{NaOH}$ is dissolved into $200 \mathrm{~mL}$ of demineralized water in a $600 \mathrm{~mL}$ beaker. Then $70 \mathrm{~mL}$ of $50 \% \mathrm{H} 2 \mathrm{O} 2$ was added to the beaker. The color of the solution changes from black to brownish-yellow. The mixture then irradiated with medium heat for 2 minutes in the microwave. The solution is then centrifuged to separate the aggregate. Non-doped Carbon Nanodots (CNDs) are made like the steps above but without the addition of urea

Fluorescence Analysis. The fluorescence properties of N-doped CNDs were visually analyzed using UV lamps with a wavelength of $365 \mathrm{~nm}$. N-doped CNDs are placed in a quartz cuvette then irradiated under $365 \mathrm{~nm} \mathrm{UV} \mathrm{light} \mathrm{to} \mathrm{see} \mathrm{the} \mathrm{fluorescence.} \mathrm{Blue} \mathrm{or} \mathrm{green}$ fluorescence indicates the presence of CNDs. Spectrum Analysis at UV Wavelength. Spectrum of N-doped CNDs at UV wavelength region $(200-400 \mathrm{~nm})$ were analyzed using the SHIMADZU UV-Vis spectrophotometer to strengthen the indication of CNDs. The resulting absorbance peaks can show the character of CNDs.

Functional Group Analysis Using FTIR. Fourier Transform Infra-Red Spectroscopy (FTIR) is used to analyze the presence of functional groups contained in N-doped CNDs analyzed by 
FTIR. $1 \mathrm{~mL}$ of N-doped CNDs and Non-doped CNDs (in different containers) were evaporated at $60^{\circ} \mathrm{C}$ to form solids. The solid was analyzed using FTIR. The Morphology Analysis Using HRTEM. High-Resolution Transmission Electron Microscopy (HRTEM) is used to determine the particle size distribution and morphology of N-doped CNDs. HRTEM analysis is carried out at the Nanoscience and Nanotechnology Research Center of the Bandung Institute of Technology. The particle size of N-doped CNDs must be below or equal to $10 \mathrm{~nm}$. N-doped CNDs particle measurements were performed using Fiji software. The standard solution of MB with a concentration of $0,1,2,3,4$, and 5 ppm was made by diluting the $100 \mathrm{ppm}$ of $\mathrm{MB}$ standard solution to create a curve calibration of MB. The MB solution sample was made with a concentration of 3 ppm by diluting 100 ppm MB solution. Degradation of MB With $254 \mathrm{~nm}$ UV Light Irradiation. In the first stage, photocatalytic degradation was carried out at $\mathrm{pH} 3.7$, and 10 by the addition of $\mathrm{N}$-doped CNDs 1,2,3,5, and $7 \mathrm{~mL}$ to determine the optimum $\mathrm{pH}$ and volume of $\mathrm{N}$-doped CNDs to degrade MB by photocatalytic.

Into different beaker glass containing $50 \mathrm{~mL}$ of $3 \mathrm{ppm} \mathrm{MB}$ solution, $\mathrm{N}$-doped CNDs were added with volumes of 1,2 , and $3 \mathrm{~mL}$. $\mathrm{NaOH} 0.1 \mathrm{~N}$ and $\mathrm{HCl} 0.1 \mathrm{~N}$ were then added to adjust the $\mathrm{pH}$ value of the mixture. Before irradiation using $254 \mathrm{~nm}$ UV light, the mixture was stirred using magnetic stirring for 30 minutes in the dark to achieve equilibrium of MB adsorption on the surface of N-doped CNDs. Then the sample is taken within 30 minutes. The photocatalytic process was carried out for 270 minutes with sampling intervals every 60 minutes in a photoreactor containing $254 \mathrm{~nm} 11 \mathrm{~W}$ UV lamps and 14.5 W Philips LEDs which were $40 \mathrm{~cm}$ away from the surface of the MB sample. Stirring is done using a magnetic stirrer to maintain the homogeneity of the mixture. When the optimum $\mathrm{pH}$ conditions are known, 5 and $7 \mathrm{~mL} \mathrm{~N}$ doped CNDs are added to determine the optimum N-doped CNDs volume conditions. MB concentration was determined using Labo visible spectrophotometer at a maximum wavelength of $660 \mathrm{~nm}$. Degradation of Methylene Blue Using Visible Light

At this stage, the MB sample with a concentration of 3 ppm was degraded for 270 minutes at the optimum $\mathrm{pH}$ and volume of $\mathrm{N}$-doped CNDs in the same procedure as the first stage but by using a $14.5 \mathrm{~W}$ Phililps LED as a light source. As a control variable, the photocatalytic degradation process of 3 ppm MB was also carried out using Non-doped CNDs (without nitrogen doping) as photocatalyst, and carried out at optimum conditions using 14.5 W Phililps LED lamps as a light source.

\section{Result and Discussion}

\subsection{Synthesis of N-doped Carbon Nanodots}

$\mathrm{N}$-doped CNDs were synthesized from cane molasses using hydrogen peroxide followed by Microwave-Assisted Extraction method in alkaline solution by adding the $\mathrm{NaOH}$ into a mixture. The $46 \%$ urea was used as a nitrogen dopant of CNDs to enhance the activity of CNDs under visible light irradiation. In the alkaline solution, the $\mathrm{OH}_{2}$ was produced which contributes to oxidizing the molasses mixture. The color of the molasses mixture turn from a black suspension into a yellowish suspension. The synthesis process was immediately continued by microwave irradiation of the yellowish suspension at medium heat level for 2 minutes. The suspension was centrifugated at $5000 \mathrm{rpm}$ for 5 minutes to remove the aggregates which are form during the processes of synthesis. The yellowish transparent solution of CNDs established after the centrifugation of the suspension. 


\subsection{Characterization of $\mathbf{N}$-doped CNDs}

The N-doped CNDs solution exhibit a green and blue fluorescence under $365 \mathrm{~nm}$ UV light irradiation as shown in Figure 2.

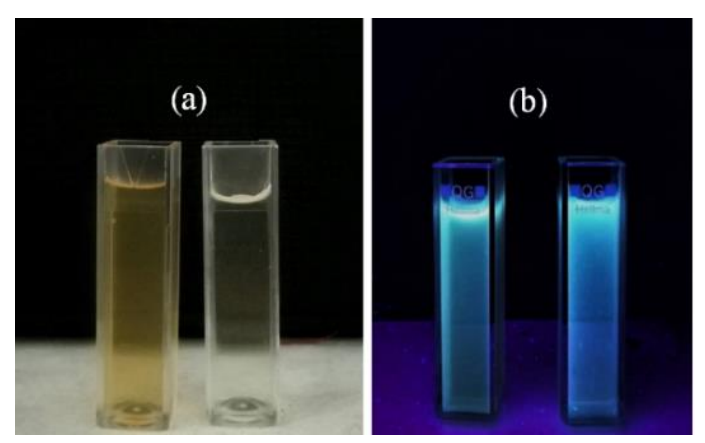

Fig. 2. The fluorescence of N-doped CNDs under visible light (a) and UV light $365 \mathrm{~nm}$ irradiation $($ left $=$ concentrate, right $=$ dilute $)$.

This is the first indication that the CNDs have been formed. This fluorescence phenomenon is caused by the $365 \mathrm{~nm}$ UV light that absorbed by N-doped CNDs cause the electron to excite from valence band to conductive band of N-doped CNDs. Because of the instability of occupation of the electron in the conductive band, the electron then back to the valence band by releasing the energy which emits a blue fluorescence. In determining the fluorescence characteristic of N-doped CNDs, the dilution of N-doped CNDs solution was carried out (1:5) using aqua DM to prevent agglomeration and aggregation. In high concentration of $\mathrm{N}$-doped CND solution (without dilution) the green fluorescence of N-doped CNDs are appear under 365 nm UV light. The green fluorescence indicates the agglomeration and aggregation have occurred in the solution of $\mathrm{N}$-doped CNDs that contribute to the forming of nanocluster which the diameter of the particle is bigger than its primary particle [7] that means the big particles of $\mathrm{N}$ doped CNDs have been formed. This aggregation decreases the emission of N-doped CNDs[2]. The lack of the absorption of UV light which is caused by the decreasing of the surface area of $\mathrm{N}$-doped CNDs resulted in lower emission under $365 \mathrm{~nm}$ UV light irradiation.

While the dilute solution of N-doped CNDs exhibits a blue fluorescence under UV light $365 \mathrm{~nm}$ irradiation. The smaller of the particle the bluer of the fluorescence that appears under $365 \mathrm{~nm}$ UV light. These phenomena indicate that the dilute solution of N-doped CNDs showed its primary particle which is smaller than in the concentrate solution. The UV-Vis absorption spectrum of $\mathrm{N}$-doped CNDs showed a strong absorption band under $300 \mathrm{~nm}$ with a maximum wavelength at $220 \mathrm{~nm}$ which is attributed to $\pi-\pi^{*}$.transition. Moreover, a weak absorption tail between 300 and $400 \mathrm{~nm}$ was also observed, attributable to the $n-\pi^{*}$ transitions of heteroatom ( $\mathrm{N}$ and $\mathrm{O}$ )-containing bonds [8].

The UV spectrum of N-doped CNDs as shown in Figure 3. 


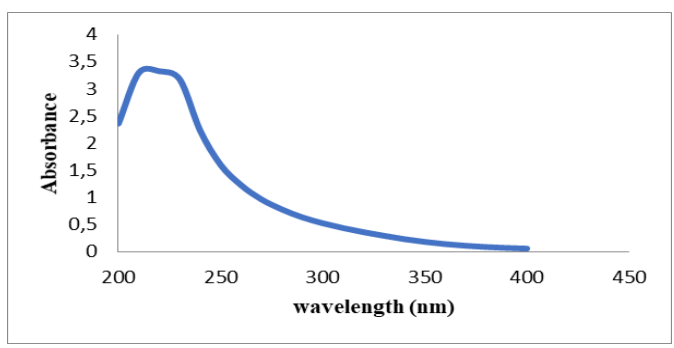

Fig. 3. The UV spectrum of N-doped CNDs.

The functional groups of N-doped CNDs were analyzed using FTIR. The vibration peaks of $\mathrm{OH}, \mathrm{C}-\mathrm{H}, \mathrm{C}=\mathrm{O}, \mathrm{N}-\mathrm{H}$, and $\mathrm{C}-\mathrm{N}$ functional groups are observed by FTIR at wavenumbers $3246.94 \mathrm{~cm}-1,2929.06 \mathrm{~cm}-1,1656.08 \mathrm{~cm}-1,1590.27 \mathrm{~cm}-1$, and $1036.98 \mathrm{~cm}-1$ respectively as shown in Figure 3. These functional groups reveal the presence of hydrophilic groups over Ndoped CNDs leading to the excellent water dispersibility as shown in Figure 4.

The success of nitrogen doping within CNDs is proven by FTIR analysis showing an increase of absorbance of C-N and N-H groups of N-doped CNDs. The absorbance of C-N and $\mathrm{N}-\mathrm{H}$ functional groups of N-doped CNDs at wavenumber 1036,98 cm-1 and 1590,27 cm-1 are higher than the absorbance of $\mathrm{C}-\mathrm{N}$ and $\mathrm{N}-\mathrm{H}$ functional groups of Non-doped CNDs at wavenumber 1037,62 cm-1 dan 1587,66 cm-1 as shown in Figure 5.

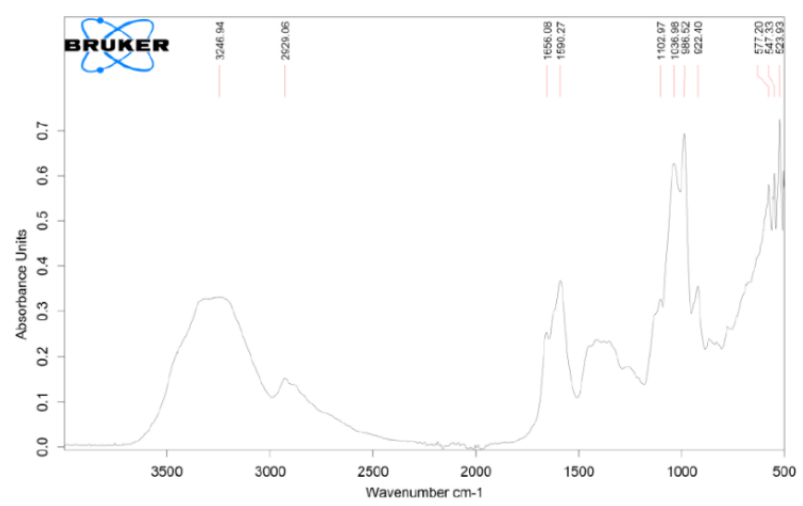

Fig. 4. FTIR analysis of N-doped CNDs. 


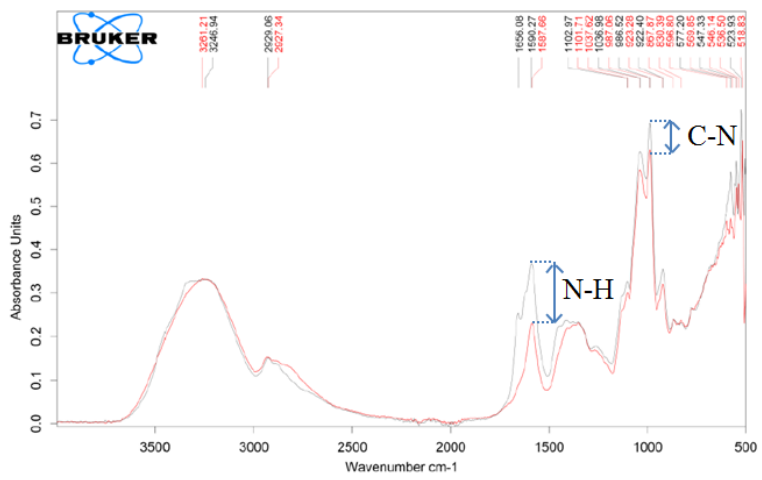

Fig. 5. Comparison of the Infra-red spectrum of N-doped CNDs (black) and Non-doped CNDs (red).

The nanostructure of N-doped CNDs were analyzed using HRTEM. The HRTEM image shows the tiny dots of N-doped CNDs and uniform in size which are showed in Figure 6. An average of synthesized $\mathrm{N}$-doped CNDs is $1,5 \mathrm{~nm}$ with overall size distribution from 1,33-1,46 $\mathrm{nm}$ as shown in Figure 7.

\subsection{Influence of Photocatalyst Amount}

The influence of N-doped CNDs amount on the degradation of 3 ppm Methylene Blue (MB) through photocatalytic was investigated with the variation of the addition of $1,2,3,5$, and $7 \mathrm{~mL}$ of N-doped CNDs. The efficiency of MB degradation is dependent on N-doped CNDs concentration. With increasing photocatalyst concentration, the adsorbed of dye molecules and the number of photons absorbed increased which lead to increase the efficiency degradation. The results showed that the degradation efficiency of methylene blue using $3 \mathrm{~mL} \mathrm{~N}$-doped CNDs exhibited the most optimal degradation efficiency up to $96,8 \%$ as shown in Figure 8 .

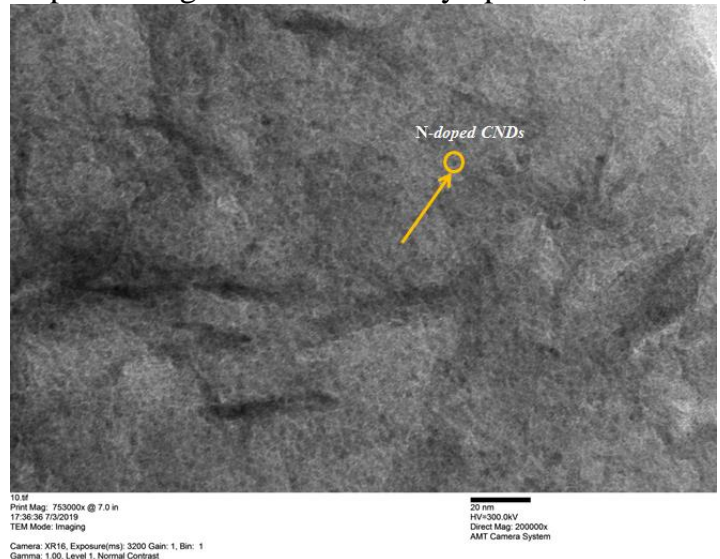

Fig. 6. HRTEM image of N-doped CNDs. 


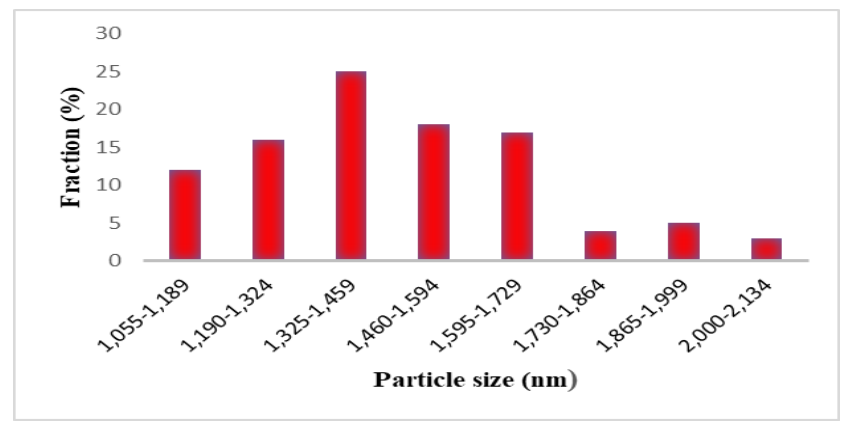

Fig. 7. The Size Distribution of N-doped CNDs.

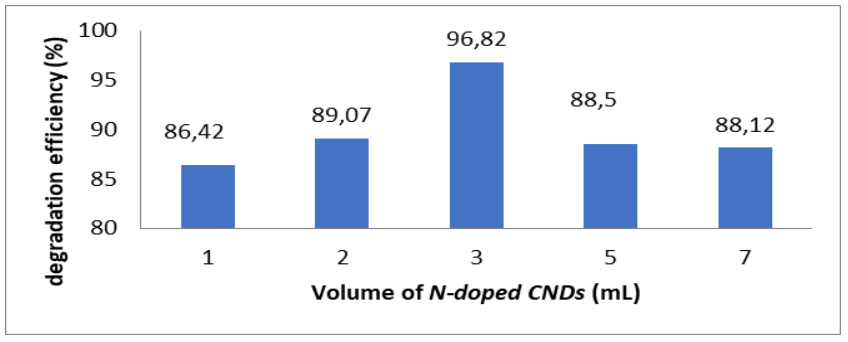

Fig. 8. Effect the amount of N-doped CNDs on degradation efficiency of MB.

However, the efficiency of $5 \mathrm{~mL}$ and $7 \mathrm{~mL} \mathrm{~N}$-doped CNDs addition showed the decreasing of efficiency as showed in Figure 6. these phenomena are caused by the exceeded of photocatalyst that increases the turbidity of MB solution. The agglomerate that is formed during the degradation leads to increasing of turbidity in the solution which decreases the light penetration and consequently, the degradation is less effective [9].

\subsection{The Influence of $\mathrm{pH}$}

The effect of $\mathrm{pH}$ on the degradation of $3 \mathrm{ppm} \mathrm{MB}$ through the photocatalytic process was investigated. The degradation of $3 \mathrm{ppm} \mathrm{MB}$ was carried out in acidic, neutral, and alkaline condition ( $\mathrm{pH} 3, \mathrm{pH} 7$, and $\mathrm{pH} 10)$. The result showed that the highest degradation efficiency of MB exhibits in alkaline condition ( $\mathrm{pH} 10)$ as shown in Figure 9.

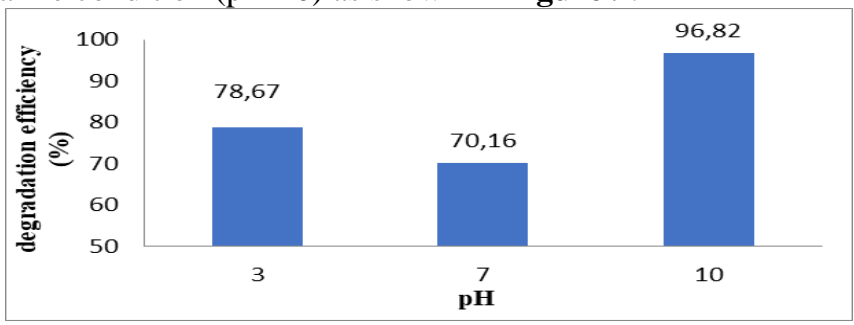

Fig. 9. The influence of $\mathrm{pH}$ on degradation efficiency of MB.

The degradation efficiency of $\mathrm{MB}$ at $\mathrm{pH} 10$ was $96,8 \%$. Meanwhile, at $\mathrm{pH} 3$ and $\mathrm{pH} 7$ the degradation efficiency was lower that is $78,7 \%$ and $70,2 \%$. The exceeded of hydroxyl ion $(\mathrm{OH}-$ 
) in alkaline solution promotes the production of hydroxyl radical $(\mathrm{OH} \bullet)$ which is one of the oxidizing agents in the solution that contributes in the degradation of MB through the photocatalytic process [10]. Hydroxyl radicals are produced from the reaction of $\mathrm{OH}$ - and hole. Hole $(\mathrm{h}+)$ is formed from the photocatalytic process on the surface of N-doped CNDs. When $\mathrm{N}$-doped CNDs were irradiated by the light which has higher energy than the bandgap of Ndoped CNDs, the electron on the surface would be exited to the conductive band leaving the hole behind on the valence band ${ }^{1}$. This hole then reacts with $\mathrm{OH}$ - to produce hydroxyl radical which degrade MB into degradation product. Besides, at the alkaline condition, the higher amount of MB molecule is adsorbed on the surface of photocatalyst than at acidic and neutral condition. The highly negative charge in the alkaline solution make N-doped CNDs become negatively charged [5], thus the MB which is a cationic dye with a positive charge can be adsorbed on the surface of the highly negative charged N-doped CNDs. This phenomenon is also proved and fully matched with the previously published reports.

In the acidic condition ( $\mathrm{pH} 3$ ), the photocatalyst is protonated [11]. Thus, the MB which has a positive charge cannot be adsorbed on the surface of N-doped CNDs optimally because of the repulsion electrostatic that take place between the positively charged N-doped CNDs and MB. However, the degradation efficiency of $\mathrm{MB}$ at $\mathrm{pH} 3$ is better $(78,7 \%)$ than at neutral condition $(70,2 \%)$. The exceeded of $\mathrm{H}+$ in the acidic solution can react with the superoxide ion in the solution to produce hydroxyl radical which contribute in the degradation of MB, while at neutral condition nor $\mathrm{H}+$ and $\mathrm{OH}-$ are presence excessively which lead to less optimal degradation of MB.

\subsection{The Influence of Light Sources}

The effect of light source on degradation efficiency of $3 \mathrm{ppm}$ MB solution was carried out using UV $254 \mathrm{~nm} 11 \mathrm{~W}$ and LED Philips 14,5 W. MB under the optimal condition (pH 10 and $3 \mathrm{~mL}$ of N-doped CNDs). The result exhibit that the usage of LED Philips 14,5 W in degradation of 3 ppm MB was higher $(97,2 \%)$ than the UV $254 \mathrm{~nm} 11 \mathrm{~W}(96,8 \%)$ that usage as a light souurce as shown in Figure 10.

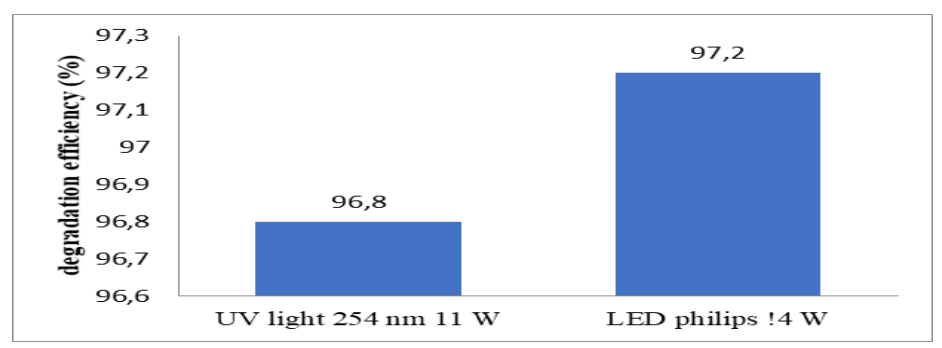

Fig. 10. The influence of light sources on degradation efficiency of MB.

Even though the UV light with $254 \mathrm{~nm}(11 \mathrm{~W})$ has a higher energy because of its short wavelength, but the higher intensity of LED Philips 14,5 W which equivalent with $120 \mathrm{~W}$. At high light intensities more photons are emitted per unit time thus, the chances of photon activation on catalyst surface increase and therefore the photocatalytic power to degrade MB is stronger [12].

The Comparison of N-doped CNDs and Non-doped CNDs, The degradation efficiency of $\mathrm{MB}$ using N-doped CNDs through the photocatalytic process under visible light irradiation 
(14,5 W LED Philips ) was compared by the Non-doped CNDs (without nitrogen dopping). The efficiency of N-doped CNDs is higher $(97,2 \%)$ than the Non-doped CNDs $(96,8 \%)$ in degrading $3 \mathrm{ppm}$ of MB solution through the photocatalytic process as shown in Figure 11.

The doping of nitrogen in photocatalyst contributes to increasing its conductivity which enhances the electron transfer process [13]. Besides, the addition of nitrogen also reduces the bandgap energy of photocatalyst [14], thus enhance the degradation efficiency of MB through photocatalytic under visible light irradiation.

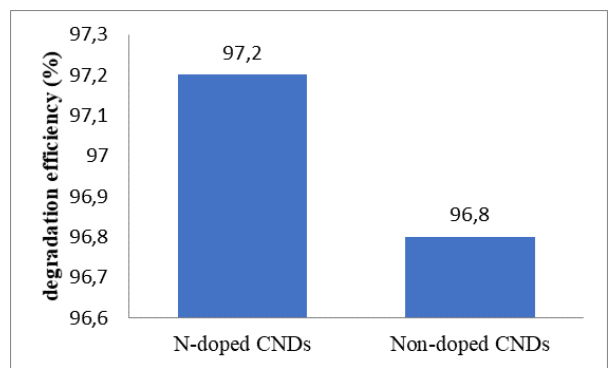

Fig. 11. The comparison of degradation efficiency of N-doped CNDs and Non-doped CNDs in degrading MB

\section{Conclusion}

$\mathrm{N}$-doped CNDs which has 1,5 particle size, blue fluorescence under UV light $360 \mathrm{~nm}$, peak absorption at $220 \mathrm{~nm}$ wavelength, and the functional group of $\mathrm{OH}, \mathrm{C}=\mathrm{O}, \mathrm{C}-\mathrm{N}$, and $\mathrm{N}-\mathrm{H}$ has been successfully synthesized from molasses using MAE method. The optimum condition of photocatalytic degradation of $\mathrm{MB}$ exhibited at $\mathrm{pH} 10$ with the addition of $3 \mathrm{~mL} \mathrm{~N}$-doped CNDs under 14,5 W Philips LED irradiation with 97,2\% degradation efficiency.

Acknowledgements. This research was funded by UPPM Politeknik Negeri Bandung.

\section{References}

[1] Umoren, S. A., Etim, U. J., and Israel, A. U.: Adsorption of methylene blue from industrial effluent using poly (vinyl alcohol). J. Mater. Environ. Sci, Vol. 4, No.1, pp. 75-86 (2013)

[2] Sciortino, A., Cannizzo, A., and Messina, F.: Carbon nanodots: A review-from the current understanding of the fundamental photophysics to the full control of the optical response. C-Journal of Carbon Research, Vol.4, No. 4, pp. 67 (2018)

[3] Houas, A., Lachheb, H., Ksibi, M., Elaloui, E., Guillard, C., and Herrmann, J. M. Photocatalytic degradation pathway of methylene blue in water. Applied Catalysis B: Environmental, Vol. 31, No. 2, pp. 145-157 (2001)

[4] Nickheslat, A., Amin, M. M., Izanloo, H., Fatehizadeh, A., and Mousavi, S. M.: Phenol photocatalytic degradation by advanced oxidation process under ultraviolet radiation using titanium dioxide. Journal of environmental and public health (2013)

[6] Azeez, F., Al-Hetlani, E., Arafa, M., Abdelmonem, Y., Nazeer, A. A., Amin, M. O., and Madkour, M.: The effect of surface charge on photocatalytic degradation of methylene blue dye using chargeable titania nanoparticles. Scientific reports, Vol. 8, No. 1, pp. 1-9 (2018) 
[7] Das, B., Dadhich, P., Pal, P., Srivas, P. K., Bankoti, K., and Dhara, S.: Carbon nanodots from date molasses: new nanolights for the in vitro scavenging of reactive oxygen species. Journal of Materials Chemistry B, Vol. 2, No. 39, pp. 6839-6847 (2014)

[8] Liu, H., Zhao, X., Wang, F., Wang, Y., Guo, L., Mei, J., Yang, X.. and Zhao, D.: High-efficient excitation-independent blue luminescent carbon dots. Nanoscale research letters, Vol. 12, No. 1, pp. 17 (2017)

[9] Wu, F., Su, H., Wang, K., Wong, W. K., \& Zhu, X.: Facile synthesis of N-rich carbon quantum dots from porphyrins as efficient probes for bioimaging and biosensing in living cells. International journal of nanomedicine, Vol. 12, pp. 7375 (2017)

[10] Soltani, N., Saion, E., Hussein, M. Z., Erfani, M., Abedini, A., Bahmanrokh, G., Navasery, M., and Vaziri, P.: Visible light-induced degradation of methylene blue in the presence of photocatalytic $\mathrm{ZnS}$ and CdS nanoparticles. International journal of molecular sciences, Vol. 13, No. 10, pp. 12242 12258 (2012)

[11] Malini, F. A., and Putri, E. M. M.: Kinetika Oksidasi Fotokatalitik Metilen Biru dengan Katalis Semikonduktor TiO2. J. SAINS DAN SENI POMITS, Vol. 2, No. 1, pp. 1-7 (2014)

[12] Rahman, M. A., Amin, S. R., and Alam, A. S.: Removal of methylene blue from waste water using activated carbon prepared from rice husk. Dhaka University Journal of Science, Vol. 60, No. 2, pp. 185-189 (2012)

[13] Reza, K. M., Kurny, A. S. W., and Gulshan, F. (2017). Parameters affecting the photocatalytic degradation of dyes using TiO 2: A review. Applied Water Science, Vol. 7, No. 4, pp. 1569-1578 (2017)

[14] Yang, G., Chen, H., Qin, H., Zhang, X., and Feng, Y.: Effect of nitrogen doping on the catalytic activity of activated carbon and distribution of oxidation products in catalytic wet oxidation of phenol. The Canadian Journal of Chemical Engineering, Vol. 95, No. 8, pp. 1518-1525 (2017)

[13] Ansari, S. A., Khan, M. M., Ansari, M. O., and Cho, M. H.: Nitrogen-doped titanium dioxide (Ndoped $\mathrm{TiO} 2$ ) for visible light photocatalysis. New Journal of Chemistry, Vol. 40, No.4, pp. 3000-3009 (2016) 